\title{
Formulation and Optimization of Controlled Release 5-Fluoro- uracil Tablets for Colonic Delivery
}

\author{
Moumita Das ${ }^{\text {* }}$, Bijaya Ghosh ${ }^{2}$, Swapnoleena Sen ${ }^{1}$, L. K. Ghosh ${ }^{1}$ \\ 'Department of Pharmaceutical Technology, Jadavpur University, Kolkata-700032, West Bengal, INDIA. \\ ${ }^{2}$ NSHM College of Pharmaceutical Technology, 124 BL Saha Road, Kolkata- 700053, West Bengal, INDIA.
}

\begin{abstract}
Objective: Formulations were developed for targeted controlled delivery of 5-fluorouracil at the colonic site. Methods: Probable dose for drug loading in the tablets and duration of drug release at the colon was determined. Core tablets were formulated with an aim to deliver the drug at a constant rate following zero order kinetics throughout the duration of release. Hydroxypropyl methylcellulose E15 and potassium chloride were incorporated as hydrophilic agents in the core matrix for drug release at the desired level and the formulation with the best release profile was chosen for coating with a coating solution containing Eudragit S100, polyethylene glycol 400 and talc. The amounts of Eudragit S100 and weight gain of the tablet were optimized using sequential simplex optimization method. Results: The optimized coated formulation $(0.6875 \mathrm{~g}$ of Eudragit S100; 7.5\% weight gain) was able to provide minimum drug release in the $5 \mathrm{hr}$ lag time $(5.9 \%$ of cumulative release) and an average release rate of $19.8 \%$ per hr thereafter. Conclusion: The optimized formulation for 5-Fluorouracil delivery at the colonic site was able to achieve a sufficient lag time and controlled drug
\end{abstract}

release and can be highly beneficial for optimum therapeutic activity and negligible side effects when administered orally.

Key words: Colonic delivery, Eudragit S100, Hydroxypropyl methylcellulose E15, Potassium chloride, Sequential optimization, Zero order release.

Key Message: Colon Targeted Controlled Release 5-Fluorouracil Tablets.

Correspondence :

Moumita Das, Department of Pharmaceutical Technology, Jadavpur University, Kolkata- 700032, West Bengal, INDIA.

Phone no: +91 9051117332

Email: mmtdas@yahoo.co.in

DOI: 10.5530/jyp.2017.9.38

\section{INTRODUCTION}

Colon cancer starts as a polyp in the innermost lining of the colon and gradually spreads beyond the inner wall into the muscle layer and reaches the adjacent lymph node of the colon and finally to the other organs (metastatis). Treatment includes surgical removal of tumors, radiation therapy and chemotherapy with antineoplastic agents like 5-fluorouracil, leucovarin, oxaliplatin, capecitabine, etc. ${ }^{1}$

5-Fluorouracil (5-FU) is an analogue of uracil and is used for the treatment of gastrointestinal cancers, including colorectal cancers, breast, gynaecological as well as head and neck tumors. ${ }^{2}$ The drug shows rapid elimination with a half-life of only $11 \mathrm{~min} .{ }^{3}$ Further, the drug is administered intravenously (IV) because of its poor absorption and variable first-pass hepatic catabolism. ${ }^{4}$

Administered as IV infusion, the drug spreads to the whole body. Eventually, the major amount of drug gets wasted resulting in severe toxicity. Leukopenia, diarrhoea, stomatitis, and nausea are common manifestations, while life threatening cardiac toxicity is reported occasionally. The drug undergoes high $(>80 \%)$ first pass metabolism which makes the drug unsuitable for conventional oral delivery. ${ }^{2}$ However, targeted delivery into tumour bearing colon can minimize these side effects and is thought to be a strategic approach to make the drug orally deliverable. Tumour vasculature in cancerous cells is leaky and absorbs rapidly. ${ }^{5}$ If the drug is present in sufficient concentration in colon, it will come into direct contact with the projected parts of the inner layer and get absorbed through the tissues, which may be also be affected in later stages of the cancer. Therefore, preferential absorption into the cancerous tissue rather than normal cells is a strong possibility.
Thus, the present study was undertaken with the objective of developing a biphasic tablet that would supress the drug release in stomach and intestine and shows a burst release at colon.

Now, it leads to three questions. 1) How to suppress the drug release in the upper parts of the gastrointestinal tract? 2) What should be that concentration in the colonic fluid to generate proper local and systemic action? 3) What should be mechanism of drug release from the formulation? The answer to the first question may be delayed drug delivery through coating, which may help to avoid drug release in the stomach and small intestine and release the drug in the colon. Enteric coated dosage forms for the drug, like matrix tablets, microspheres or nanoparticles using polymers like Eudragit S100 or ethylcellulose have been used for such purposes..$^{6-9}$ Besides, novel drug delivery systems like modified pulsincap delivery, polyelectrolyte complexes, osmotic devices, etc were also tried out. ${ }^{10-12}$

The answer to the second question may be determined by analysing available literature of drug dosing and pharmacokinetic data.

IV infusion of $5-\mathrm{FU}$ is given at a constant rate ( $40 \mathrm{drops} / \mathrm{min}$ for a total duration of $4 \mathrm{~h}$ ) such that the concentration of drug in blood remains constant. Therefore, the answer to the third question may be maintaining a constant drug concentration in the colonic fluid given through an oral dosage form, releasing drug through zero order mechanics. Thus, the present study was undertaken with the following objectives.

a) To determine the drug concentration to be maintained in the colonic fluid and the drug dosing for the tablet. 
b) To maintain a sufficient lag time for drug release by enteric coating and thereafter to maintain a constant drug release rate throughout the release period.

c) To optimize the coating parameters to achieve the desired release.

\section{MATERIALS AND METHODS}

\section{Materials}

5-Fluorouracil was purchased from Tokyo Chemical Industry Co. Ltd. Microcrystalline cellulose (MP Biomedicals); Hydroxypropyl methylcellulose E15 LV, Magnesium stearate, Sodium hydroxide, Polyethylene glycol (Loba Chemie); Polyvinylpyrrolidone (CDH Labs); Eudragit S100 (Yarrow Chemicals Pvt. Ltd., Mumbai); Talc (New Bengal Drug House); Acetone, Iso-propanol (Nice Chemicals Pvt. Ltd.); Potassium chloride, Potassium dihydrogen phosphate, Hydrochloric acid (Merck Specialities Pvt. Ltd.) were obtained commercially. Double distilled water was used throughout the study.

\section{Methods}

\section{Determination of drug concentration using pharmacokinetic data}

The required drug concentration at the colonic site was determined from available literature and pharmacokinetic data of the drug. Thereafter, the drug loading of the tablet was calculated.

\section{Formulation development}

The tablets were developed in two stages. First, formulation of the core tablets (uncoated) and second, coating. The core tablets were developed by trial error method to achieve a minimum hardness of $5 \mathrm{~kg} / \mathrm{cm}^{2}$ but rapid dissolution when placed in $\mathrm{pH} 7.4$ phosphate buffer. However, the composition of the coating solution was optimized by sequential simplex method.

\section{Preparation of the core tablets}

Core tablets were developed by conventional wet granulation method. Calculated amounts of the drug and excipients were thoroughly mixed and passed through a sieve (\#40). Next, the sifted mixture was granulated with aqueous PVP-K 30 . The prepared granules were dried, sifted through \#20, mixed with magnesium stearate and compressed in a tableting machine (16 station Cadmach compression machine). The compositions of the core tablets are outlined in Table 1.

\section{Evaluation of the core tablets}

The core tablets were tested for hardness, weight variation, content uniformity and in-vitro dissolution by standard procedure. ${ }^{13}$ Hardness was tested with Monsanto hardness tester on a batch of six tablets. Weight variation was done for tablets of the optimized formulation. For content uniformity, tablets were crushed, extracted with $\mathrm{HCl}$ buffer $(\mathrm{pH} 1.2)$ and absorbances noted at $242.9 \mathrm{~nm}$, after suitable dilution.

The drug release was tested in USP Dissolution apparatus 2 using $500 \mathrm{ml}$

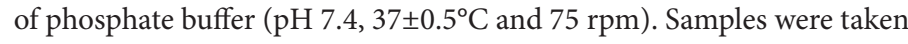
from the dissolution flask at regular intervals and the media was replenished with fresh buffer. Core tablets showing the desirable release characteristics were forwarded to the stage of coating.

\section{Determination of drug release mechanism based on study of release kinetic models}

The drug release data were fitted into the equations for zero order, first order, higuchi model and korsemeyer-peppas model. For zero order plotting, cumulative percentage drug release was plotted vs time. For first order plotting, log of cumulative percentage drug release was plotted vs time. For higuchi model plot, cumulative percentage drug release was plotted vs square root of time. For korsmeyer-peppas plot, first $60 \%$ of drug release was considered and log cumulative percentage drug release versus $\log$ time was plotted. ${ }^{14,15}$

\section{Coated tablet formulation, evaluation and optimization Procedure for coating}

For coating, the tablets were dipped into a polymer solution followed by air drying. The coating solution consisted of a mixture of Eudragit S100 (polymer), Polyethylene glycol 400 (plasticizer) and talc. A mixture of isopropanol (IPA) and acetone (1:1) served as the solvent. ${ }^{16}$

Briefly, Polyethylene glycol (PEG) at $20 \% \mathrm{w} / \mathrm{w}$ of polymer was dissolved in IPA-acetone mixture to obtain a clear solution. Next, Eudragit S100 (ES) was added in small amounts so as to dissolve the polymer. Finally, talc $(10 \% \mathrm{w} / \mathrm{w}$ of polymer) was added to reduce tackiness and stickiness of Eudragit films. ${ }^{17}$ The mixture was stirred for $2 \mathrm{hr}$ for plasticization of the polymer. The coating mixture was filtered through Whatman filter paper and used for coating.

\section{Evaluation of the coated tablets}

Coated tablets were evaluated for drug release in three different media. USP Dissolution apparatus 2 was used. The dissolution test started with $\mathrm{pH} 1.2 \mathrm{HCl}$ buffer. After $2 \mathrm{hr}$ in the $\mathrm{HCl}$ buffer, the tablets were withdrawn from the media and dissolution was carried out in $\mathrm{pH} 6.8$ phosphate buffer for two more hours. At the end of $2 \mathrm{hr}$, this media was replaced by $\mathrm{pH} 7.4$ phosphate buffer and dissolution continued for five more hours. The total duration of the study was $9 \mathrm{hr}$.

\section{Optimization of coating formulation by sequential simplex method}

Sequential simplex optimization is a simple process of optimization by which the desirable formulation would be achieved. Through this process, an optimized formula was obtained with lesser number of experiments and less wastage of drugs and excipients. In the present study, the process was started with three initial coating formulations (Table 2), designed according to the method of half factorial. The factors that were considered for the optimization were: 1. concentration of polymer, ES (F1); 2. Percentage weight gain of the tablets (F2). The rest of the factors were kept constant. Suitable drug release tests were conducted and the responses of the formulations were calculated by evaluating the response parameters, namely, cumulative drug release within the first $5 \mathrm{hr}(\mathrm{P} 1)$; average release rate from $6^{\text {th }} \mathrm{hr}$ onwards (P2). The response data generated from the dissolution experiments were normalized with the following equations (Eq 1 and 2). The normalized responses were then fitted into a final equation (Eq 3$)$ to obtain the overall response of the formulations. ${ }^{18}$

$$
\mathrm{R} 1=\frac{(\mathrm{H}-\mathrm{X})}{(\mathrm{H}-\mathrm{M})} \times 100
$$

Equation 1 was used to normalize the values for the cumulative drug release within the first $5 \mathrm{hr}(\mathrm{P} 1)$. Here, $\mathrm{H}$ and $\mathrm{M}$ were the maximum ( $10 \%$ cumulative release) and minimum ( $0 \%$ cumulative release) values set for P1 and X was the value of P1 obtained through the dissolution experiment. R1 was the normalized response for P1.

$$
\mathrm{R} 2=\frac{(\mathrm{X}-\mathrm{M})}{(\mathrm{H}-\mathrm{M})} \times 100
$$

Similarly, Equation 2 was used to normalize the values for the average rate of drug release after $5 \mathrm{hr}$ of dissolution (P2).

$$
\mathrm{Rt}=0.5 \times(\mathrm{R} 1+\mathrm{R} 2)
$$

Equation 3 was used to obtain the overall normalized response, Rt. In this equation, equal weightage was given to both $\mathrm{P} 1$ and $\mathrm{P} 2$, for optimization of the formulation. Rt was used to compare the efficiency of the formulations as to achieve the set targets. 
New formulations were developed based on the overall response, obtained through equations 1,2 and 3, according to the rules of sequential optimization. In this process, the three initial formulations (CF1, CF2 and CF3) were evaluated as described in the previous section and the best and worst formulation was noted. The worst formulation was then to be discarded and the rest were retained. The next formula to be developed was then deduced from Rule 1.

Rule 1: $\mathrm{P}+\mathrm{P}-\mathrm{W}$; where $\mathrm{P}$ was the average value of a given factor in the retained formulations and $\mathrm{W}$ represented the value of factor in the worst formulation.

The formulation such devised was again subjected to dissolution test and the overall response was evaluated in similar way. If the response of this formulation was better than the other two retained formulations, then it would be considered the best and in such case, the next formula would be devised by Rule 2 .

Rule 2: $\mathrm{P}+[2 \times(\mathrm{P}-\mathrm{W})]$

However, if the response was the worst among the formulations, then Rule 3 was applied to get the next formula.

Rule 3: $\mathrm{P}+[0.5 \times(\mathrm{P}-\mathrm{W})]$

But, if the response was in between the worst and the best, then Rule 4 was applied to derive the next formula. Rule 4 was also applied in case of an impossible formulation. An impossible formulation would be derived with values of F1 and F2 in the negative range or such a formulation would be inappropriate to develop.

Rule 4: $\mathrm{P}-[0.5 \times(\mathrm{P}-\mathrm{W})]$

The sequence of optimization was continued until the best response (closest to the target response of 100) was achieved. ${ }^{19}$

\section{Drug-excipients compatibility studies}

Drug-excipient compatibility was studied by FTIR spectroscopy. Studies were conducted on both pure drug and samples of coated tablets by $\mathrm{KBr}$ pellet method using a Bruker Alpha T spectrophotometer.

\section{RESULTS}

\section{Determination of drug loading into tablets}

When 5-FU was administered through IV infusion, the dose was around $15 \mathrm{mg} / \mathrm{kg}$ body weight. Considering an average body weight of around $60 \mathrm{~kg}$, around $900 \mathrm{mg}$ was administered. The maximum dose that could be given was $1 \mathrm{~g}$. The infusion was given by dissolving the required amount of drug in $500 \mathrm{ml}$ solvent and administered at a rate of 40 drops/ $\mathrm{min}$ for a total duration of $4 \mathrm{hr}$. Therefore, about $4 \mathrm{mg} \mathrm{drug} / \mathrm{min}$ entered blood circulation. ${ }^{20}$

The average perfusion rate of an adult body is $5000 \mathrm{ml} / \mathrm{min}$. The average perfusion rate through the colonic tissues is $70 \mathrm{ml} / \mathrm{min} .^{21}$

Taking these parameters into consideration, the amount of drug delivered to the colonic tissues by infusion $=70 \times 4 / 5000=0.056 \mathrm{mg} / \mathrm{min}=3.36 \mathrm{mg} / \mathrm{hr}$. The reported bioavailability was $28 \%$. So, the amount delivered per hour $=3.36 / 0.28=12 \mathrm{mg}$. Therefore, $12 \mathrm{mg} / \mathrm{hr}$ might be required to be delivered to the lumen.

When 5-FU was tested on cancer cell lines, EC50 value of $106.8 \mu \mathrm{M}$ was reported. When we multiplied the value with molecular weight of the drug, $13.78 \mu \mathrm{g}$ of the drug was observed to inhibit $50 \%$ of the cell population. ${ }^{2}$

From these observations we could conclude that $12 \mathrm{mg} / \mathrm{hr}$ delivery would be sufficient to produce local as well as systemic effect. Considering incomplete absorption, protein binding or first pass effect, an overage of $3 \mathrm{mg}$ was taken, and the drug to be supplied per hour to the colonic tissues was fixed to be $15 \mathrm{mg} / \mathrm{hr}$. The drug would be supplied from the tablet upto $4 \mathrm{hr}$ (considering 4 hours given through IV infusion). Therefore the total drug loading into the tablet $=15 \times 4=60 \mathrm{mg} /$ tablet.

Therefore, the formulation to be prepared would consist of a core tablet to achieve constant drug release rate, with a coating to achieve sufficient lag time of around $5 \mathrm{hr} .15 \mathrm{mg} / \mathrm{hr}$ release would be $25 \%$ cumulative drug release/hr. Therefore, for optimization a range of $15-25 \%$ cumulative release/hr was chosen.

\section{Core tablet formulation, evaluation and optimization}

The developed core tablets had a smooth surface, with hardness ranging from $1.1 \mathrm{kp}$ (250 $\mathrm{mg}$ tablet) to $3.1 \mathrm{kp}$ (300 mg tablet). It was observed that as the amount of PVP was increased, the hardness of the core tablets increased. Further, the hardness increased with increase in amount of HPMC and tablet weight. However, after a certain amount was reached (15 mg of PVP; $90 \mathrm{mg}$ of HPMC), the hardness did not increase further. Therefore, formulation FL3 was optimized with respect to hardness. The content uniformity of all the batches was near to $100 \%$ (Table 1). Tablets of FL3 were weighed individually and the average weight was $296.49 \pm 6.72$ (Figure 1). Drug release from the core tablets was plotted (Figure 2). More than 90\% release was completed within 3 hours of dissolution. The release kinetics was determined by fitting the release data into model equations (zero order, first order, higuchi and korsmeyerpeppas models) and the $\mathrm{R}^{2}$ values of the respective plots were obtained to determine the best fitting model for drug release (Table 3). Formulation FL3 which had acceptable hardness and also produced desirable release profile following zero order kinetics, was chosen as the optimized formulation.

\section{Coated tablet formulation, evaluation and optimization}

Non-sticky coating formulations were prepared to obtain error free coating and smooth coats. The coated tablets were then evaluated by dissolution tests and the formulation with minimum release during the lag time of $5 \mathrm{hr}$ and with an average release in the range of $15-25 \%$ cumulative release/hr thereafter, was chosen as the optimum formulation. CF5 released only $5.92 \%$ drug in the first $5 \mathrm{hr}$ (lag time) and maintained an average release rate of $19.856 \%$ (20\%, approximately) was chosen as the optimum formulation (Figure 2). The formulation was optimized with the help of sequential simplex optimization method.

Table 1: Compositions of the core tablets

\begin{tabular}{ccccc}
\hline Material $(\mathrm{mg})$ & FL-1 & FL-2 & FL-3 & FL-4 \\
\hline Drug & 60 & 60 & 60 & 60 \\
HPMC E15M & 50 & 50 & 90 & 120 \\
KCl & 50 & 50 & 50 & 50 \\
MCC & 80 & 77.50 & 80 & 47 \\
PVP & 7.50 & 10 & 15 & 20 \\
Magnesium Stearate & 2.50 & 2.5 & 5 & 3 \\
Total weight of tablet & 250 & 250 & 300 & 300 \\
Hardness (kp) & $1.10 \pm 0.14$ & $1.70 \pm 0.42$ & $3.10 \pm 0.14$ & $2.85 \pm 0.49$ \\
Content uniformity (\%) & 96.67 & 99.63 & 100.32 & 102.50 \\
\hline
\end{tabular}

Table 2: Compositions of the coating formulations

\begin{tabular}{ccccccc}
\hline Factors & CF 1 & CF 2 & CF 3 & CF4 & CF5 & CF6 \\
\hline Eudragit S100 (g) & 0.75 & 0.50 & 0.75 & 0.50 & 0.68 & 1.15 \\
PEG 400 (\% w/w on ES) & 20 & 20 & 20 & 20 & 20 & 20 \\
PEG 400: Talc ratio & $2: 1$ & $2: 1$ & $2: 1$ & $2: 1$ & $2: 1$ & $2: 1$ \\
Weight gain (\%) & 9 & 9 & 6 & 12 & 7.50 & 6.75 \\
\hline
\end{tabular}




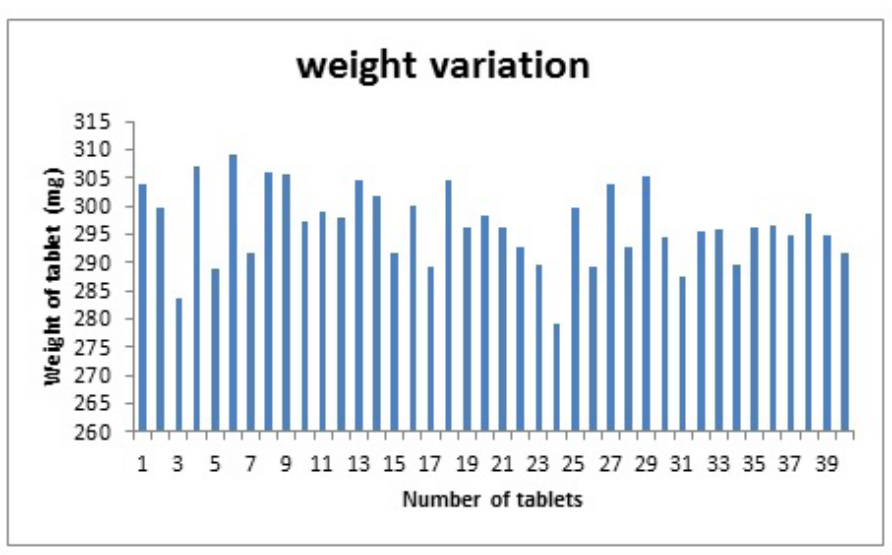

Figure 1: Weight variation of tablets (FL3).

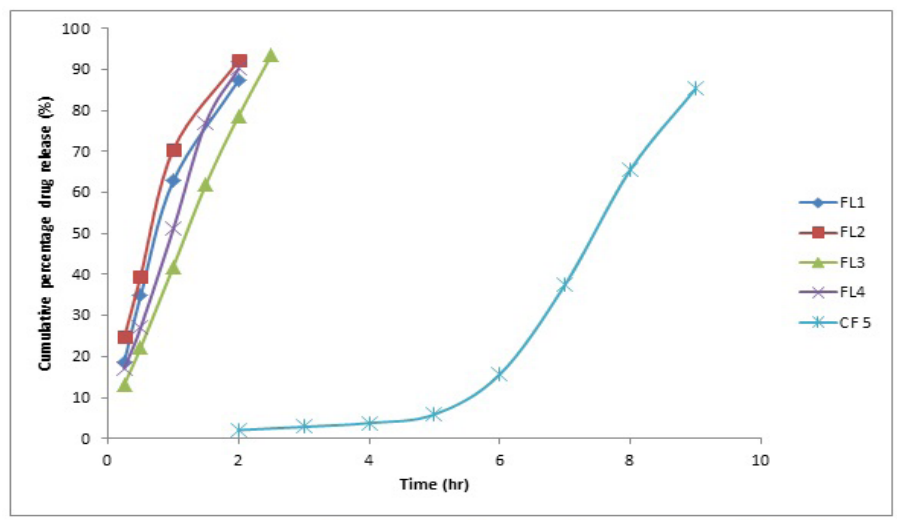

FL1, FL 2, FL 3, FL 4 are the core formulations and CF 5 is the optimized coated formulation

Figure 2: Drug release from core tablets and optimized coated formulation CF 5 .

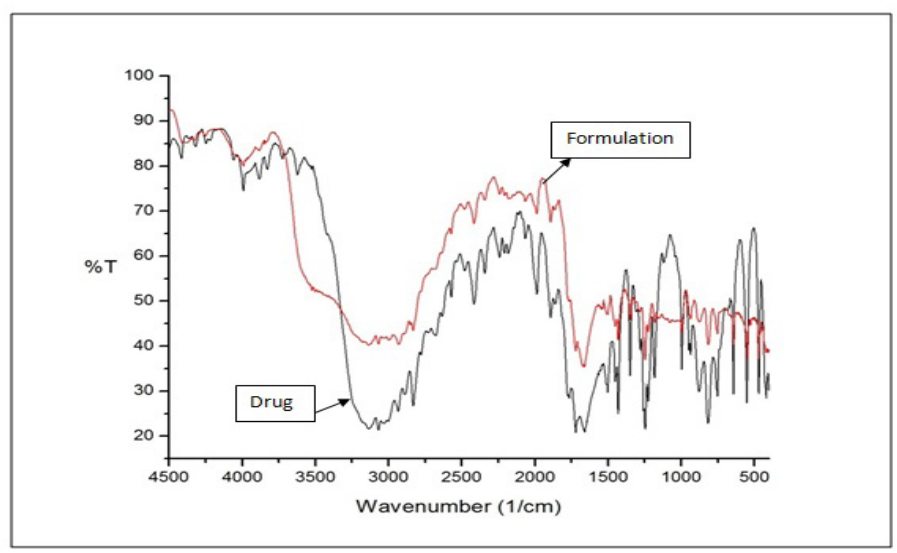

Figure 3: FTIR of drug and formulation.

Table 3: Linearity coefficients for different kinetic models

\begin{tabular}{ccccc}
\hline Release kinetic models & \multicolumn{4}{c}{$\mathrm{R}^{2}$ values } \\
\hline & FL1 & FL2 & FL3 & FL4 \\
Zero order & 0.948 & 0.932 & 0.997 & 0.989 \\
First order & 0.738 & 0.727 & 0.880 & 0.844 \\
Higuchi & 0.934 & 0.904 & 0.990 & 0.970 \\
Korsmeyer-peppas & 0.999 & 0.996 & 0.997 & 0.991 \\
'n' value & 0.873 & 0.755 & 0.851 & 0.789 \\
\hline
\end{tabular}

Determination of drug-excipients compatibility by FTIR studies

Matches between the spectra of 5-FU and formulation (CF5) were found for different functional groups. Symmetric C-H stretch bands at 2899.36 $\mathrm{cm}^{-1}$ and $2891.29 \mathrm{~cm}^{-1}$ for 5-FU and CF-5, respectively; asymmetric $\mathrm{C}-\mathrm{H}$ stretch bands at $2933.729 \mathrm{~cm}^{-1}$ and $2929.87 \mathrm{~cm}^{-1}$ for 5 -FU and CF-5, respectively; $\mathrm{C}=\mathrm{C}$ stretch bands at $1535.33 \mathrm{~cm}^{-1}$ for $5-\mathrm{FU}$ and CF-5; C-N stretch bands at $1041.56 \mathrm{~cm}^{-1}$ and $1043.48 \mathrm{~cm}^{-1}$ for $5-\mathrm{FU}$ and CF-5, respectively; C-C stretch bands at $1278.805 \mathrm{~cm}^{-1}, \mathrm{~N}-\mathrm{H}$ stretch bands at $3138.18 \mathrm{~cm}^{-1}$ and $\mathrm{C}-\mathrm{H}$ bending bands at $1348.24 \mathrm{~cm}^{-1}$ for 5 -FU and CF-5; C-N stretch bands at $1118.71 \mathrm{~cm}^{-1}$ and $1101.35 \mathrm{~cm}^{-1}$ for $5-\mathrm{FU}$ and CF-5, respectively, were observed. ${ }^{22}$ The comparable FTIR for the drug 5-FU and 5-FU tablet (CF5) was recorded (Figure 3). From, the studies, it could be concluded that 5 -FU was compatible with the excipients used in the study.

\section{DISCUSSION}

A constant drug release rate was desired for the duration of drug release. Therefore, a hydrophilic polymer, HPMC E15 was used in the core as it has been used in matrix tablets producing linear release profile. ${ }^{23} \mathrm{KCl}$ was introduced in the matrix because it was highly water soluble and would facilitate in the uptake of water in the core once the eudragit coating started to dissolve. It would facilitate to form water channels within the tablet for slow erosion of the polymer and release of the drug. Often super-disintegrants were added in the core tablets to facilitate disintegration of the granules and faster release after coating dissolved. ${ }^{6}$ This might result in certain amount of burst release rather than controlled release at a constant rate. Therefore, $\mathrm{KCl}$ was tried out alongwith HPMC E15 in the present study.

As drug release was hindered to some extent on application of coating, the target was to achieve about $90 \%$ drug release within three hours, which was achieved by all the formulations. Release kinetics of the core tablets was determined by fitting the dissolution data into zero order, first order, higuchi and korsmeyer-peppas models and finding out the respective $\mathrm{R}^{2}$ values (linearity coefficients). The value of ' $\mathrm{n}$ ' in korsmeyerpeppas equation was dependent on the geometry of the delivery system as well as the mechanism of release. The values of ' $n$ ' for a cylindrical shaped device were $<0.43$ or 0.43 for Fickian release and 0.85 for case II or zero-order release. For systems exhibiting case II transport, the dominant mechanism for drug transport was due to polymer matrix relaxation. The value of $\mathrm{n}>0.43$ but $<0.85$ was considered as anomalous transport (non-Fickian) and referred to the coupling of Fickian diffusion and polymer matrix relaxation. The value of $n>0.85$ was considered as super case II transport. ${ }^{15}$ In the present study all the formulations had the highest $\mathrm{R}^{2}$ values for zero order plots. Further, korsemeyer-peppas plots for all the formulations had good linearity (>0.99). FL1 and FL3 had ' $n$ ' values of 0.873 and 0.851 , respectively, which were representative of case II transport mechanism or zero order release. FL2 and FL4 had ' $n$ ' values of 0.755 and 0.789 , respectively. Therefore, these formulations would be having anomalous transport (non-Fickian) and referred to the coupling of Fickian diffusion and polymer matrix relaxation. Therefore, it was confirmed that FL3 followed zero order release kinetics and would give constant drug release, independent of drug concentration.

From observations of release profiles, release kinetics and hardness test, FL3 was chosen as the optimum core formulation. FL3 had an average hardness of $3.1 \mathrm{kp}$. Further, it had the best linearity among zero order plots $\left(\mathrm{R}^{2}=0.997\right)$ and ' $\mathrm{n}$ ' value of 0.851 , which confirmed the kinetics of drug release to be linear. ${ }^{15}$

\section{Coated tablet formulation, evaluation and optimization}

PEG 400 has been used as a plasticizer in ES coating solutions in amounts of $10 \% \mathrm{w} / \mathrm{w}$ on dry polymer. However, in the present study, $20 \% \mathrm{w} / \mathrm{w}$ of 
Table 4: Overall Responses (Rt) of the coating formulations

\begin{tabular}{ccccccc}
\hline Response & CF1 & CF2 & CF3 & CF4 & CF5 & CF6 \\
\hline R1 & -10.85 & 69.18 & -175.83 & 87.16 & 40.79 & -27.39 \\
R2 & 60.61 & -30.70 & 36.90 & -86.85 & 48.56 & 52.67 \\
Rt & 24.88 & 19.24 & -69.47 & 0.15 & 44.67 & 12.63 \\
\hline
\end{tabular}

PEG was used. The water uptake and permeation rates of the Eudragit film would be much higher at this concentration, which would facilitate the dissolution of the coating within $5 \mathrm{hr}$ of lag time. ${ }^{24}$ Talc was added in the coating solution in half the amount of plasticizer. ${ }^{25}$

The initial three formulations were subjected to dissolution tests and values of $\mathrm{P} 1$ and $\mathrm{P} 2$ were recorded. The responses of the parameters were initial formulations, CF3 was the worst and CF1 was the best. Therefore, $\mathrm{CF} 1$ and $\mathrm{CF} 2$ were retained and CF3 was omitted and the next formulation CF4 (with $0.5 \mathrm{~g}$ ES and 12\% weight gain) was derived with Rule 1. Thus, the next set of formulations to be evaluated consisted of CF1, CF2 and CF4. From the response calculations CF4 was found to be the worst in the set. Therefore, Rule 3 was applied for the next formulation. CF-5 was formulated with $0.6875 \mathrm{~g} \mathrm{ES}$ and $7.5 \%$ weight gain. Thus, the next set of formulations to be evaluated consisted of CF1, CF2 and CF5. The new formulation CF5 had the best response and CF2 had the worst response. Therefore, Rule 2 was applied for the next formulation, CF6, which was formulated with $1.15625 \mathrm{~g}$ ES and $6.75 \%$ weight gain. Among the formulations, CF1, CF5 and CF6, CF5 was the best (44.67) and CF 6 had the worst response (12.63). Therefore, Rule 3 was applied and the next formulation was derived with $0.5 \mathrm{~g}$ ES and $9 \%$ weight gain. But such a formulation already existed (CF2). Therefore the sequence was being repeated. Thus, the optimization was stopped at this point and batch CF5 (0.6875 ES/7.5\% wt gain) with the highest response of 44.67 was termed the optimized batch. The overall responses (Rt) of the various formulations were recorded (Table 4).

\section{CONCLUSION}

5-FU delayed release tablet with linear release profile was developed and characterized with respect to release kinetics and average drug release rate. Drug loading of $60 \mathrm{mg}$ was calculated and a suitable release rate in the range of $15-25 \%$ release per hour was desired. Sequential simplex optimization method helped to determine the optimum formulation with $5.9 \%$ release in the initial lag time of $5 \mathrm{hr}$ and an average release rate of $19.8 \%$ per hr during the entire release period. The optimized formulation would be beneficial for targeting and controlled release of 5-FU for colon cancer management.

\section{ACKNOWLEDGEMENT}

The authors would like to extend their thanks and gratitude to Council of Scientific \& Industrial Research, India for their financial support to carry out the research work.

\section{CONFLICT OF INTEREST}

The authors report no conflict of interest.

\section{ABBREVIATION USED}

5- FU: 5- Fluorouracil; IV: Intravenous; FL-1: Formulation 1; FL-2: Formulation 2; FL-3: Formulation 3; FL-4: Formulation 4; HPMC: Hydroxypropylmethylcellulose; KCl: Potassium chloride; PVP: Polyvinylthen normalized and overall responses were calculated. Among the

pyrrolidone; IPA: Isopropyl alcohol; PEG: Polyethylene glycol; HCl: Hydrochloric acid; ES: Eudragit S100; USP: United States Pharmacopoeia; CF-1: Coating formulation 1; CF-2: Coating formulation 2; CF-3: Coating formulation 3; CF-4: Coating formulation 4; CF-5: Coating formulation 5; CF-6: Coating formulation 6.

\section{REFERENCES}

1. Narola A, Spar MD, Rampertab SD. Gastrointestinal disease in men. In: Spar MD, Munoz GE, editors. Integrative Men's Health. New York: Oxford University press; 2014;284-5.

2. Focaccetti C, Bruno A, Magnani E, Bartolini D, Principi E, Dallaglio K, et al. Effects of 5-Fluorouracil on morphology, cell cycle, proliferation, apoptosis, autophagy and ROS production in endothelial cells and cardiomyocytes. PLoS One. 2015;10(2):e0115686.

3. Chabner BA, Amrein PC, Druker B, Michaelson MD, Mitsiades CS, Goss PE, et al. Chapter 51, Antineoplastic agents. In: Brunton LL, Lazo JS, Parker KL, editors. Goodman Gilman's The Pharmacological basis of therapeutics. New York: Mc Graw Hill Companies Inc.; 2006;1343-4

4. Chavez M, Nagel KM, Karash AR. Chapter 21, Oncologic disorders. In: Lee M, Desai A, editors. Gibaldi's Drug Delivery Systems in Pharmaceutical Care. Bethesda: American Society of Health system Pharmacists. 2007:378.

5. Hashizume H, Baluk P, Morikawa S, McLean JW, Thurston G, Roberge S, et al. Openings between Defective Endothelial Cells Explain Tumor Vessel Leakiness. Am J Pathol. 2000;156(4):1363-80.

6. Kumar RV, Sinha VR. Tailoring of drug delivery of 5-fluorouracil to the colon via a mixed film coated unit system. Acta Pharm. 2011;61(3):343-51.

7. Tummala S, Kumar MNS, Prakash A. Formulation and characterization of 5-Fluorouracil enteric coated nanoparticles for sustained and localized release in treating colorectal cancer. Saudi Pharm J. 2015;23(3):308-14

8. Rahman Z, Kohli K, Khar RK, Ali M, Charoo NA, Shamsher AA. Characterization of 5-fluorouracil microspheres for colonic delivery. AAPS Pharm Sci Tech. 2006;7:E47.

9. Vemula SK. Colon Specific Drug Delivery: Effect of Eudragit Enteric Coating on Hydroxypropyl Methylcellulose Matrix Tablets of Flurbiprofen. J Young Pharmacists. 2015;7(4):373-83.

10. Pandey S, Mishra A, Raval P, Patel H, Gupta A, Shah D. Chitosanepectin polyelectrolyte complex as a carrier for colon targeted drug delivery. J Young Pharmacists. 2013;5(4):160-6.

11. Patel DM, Jani RH, Patel CN. Design and evaluation of colon targeted modified pulsincap delivery of 5-fluorouracil according to circadian rhythm. Int J Pharma Investig. 2011;1(3):172-81.

12. Jose S, Dhanya K, Cinu TA, Litty J, Chacko AJ. Colon Targeted Drug Delivery: Different Approaches. J Young Pharmacists. 2009;1(1):13-9.

13. Banker GS, Anderson NR. Chapter 11, Tablets. In: Lachman L, Lieberman HA, Kanig JL, editors. The Theory and Practice of Industrial Pharmacy. Mumbai: Varghese Publishing House. 1987;297-302.

14. Dash S, Murthy PN, Nath L, Chowdhury P. Kinetic modeling on drug release from controlled drug delivery systems. Acta Pol Pharm. 2010;67(3):217-23.

15. Apu AS, Pathan AH, Shrestha D, Kibria G, Jalil R. Investigation of In vitro Release Kinetics of Carbamazepine from Eudragit@ RS PO and RL PO Matrix Tablets. Trop J Pharm Res. 2009;8(2):145-52.

16. Mehta R, Chawla A, Sharma P, Pawar P. Formulation and in vitro evaluation of Eudragit S-100 coated naproxen matrix tablets for colon-targeted drug delivery system. J Adv Pharm Technol Res. 2013;4(1):31-41.

17. Agyilirah GA, Banker GS. Polymers for controlled drug delivery. In: Tarcha PJ, editor. Polymers for enteric coated applications. Florida: CRC Press Inc.; 1991;59.

18. Ghosh B Ray S, Das M. Formulation, development and optimization of mouth dissolving tablets of Rizatriptan benzoate. J Pharm Invest. 2015;45(6):593-600.

19. Bolton S, Bon C. Pharmaceutical statistics practical and clinical applications. Informa healthcare, New York. 2009;425-52.

20. Medac $\mathrm{GmbH}$ : Fluorouracil Injection, $50 \mathrm{mg} / \mathrm{ml}$, solution for injection [Internet]. c 2000-2014. Wedel: Medac GmbH; Available from: https://www.medicines. org.uk/emc/medicine/6378.

21. Grayson J. The measurement of intestinal blood flow in man. J Physiol. 1951; 114: 419-434.

22. Gunasekaran S, Natarajan RK, Santhosam K. Spectroscopic investigation on Fluorouracil. Asian J Chem. 2003;15(3):1347-54.

23. Kim C. Release kinetics of coated, donut-shaped tablets for water soluble drugs. Eur J Pharm Sci. 1999;7(3):237-42.

24. Khodaverdi E, Tekie FSM, Amoli SS, Sadeghi F. Comparison of Plasticizer Effect on Thermo-responsive Properties of Eudragit RS Films. AAPS Pharm Sci Tech. 2012;13(3):1024-30.

25. Elbary AA, Aboelwafa AA, Al Sharabi IM. Once Daily, High-Dose Mesalazine Controlled-Release Tablet for Colonic Delivery: Optimization of Formulation Variables Using Box-Behnken Design. AAPS Pharm SciTech. 2011;12(4):1454-64.

Article History: Submission Date: 29-11-16; Received Date: 13-01-17; Acceptance Date: 21-01-17.

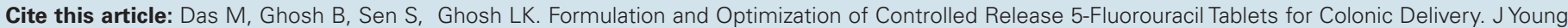
Pharm. 2017;9(2):192-6. 